\title{
The effect of habitat structure on prey mortality depends on predator and prey microhabitat use
}

\author{
Jan Klecka • David S. Boukal
}

Received: 24 January 2014 / Accepted: 25 June 2014 / Published online: 2 August 2014

(C) Springer-Verlag Berlin Heidelberg 2014

\begin{abstract}
Structurally complex habitats provide cover and may hinder the movement of animals. In predatorprey relationships, habitat structure can decrease predation risk when it provides refuges for prey or hinders foraging activity of predators. However, it may also provide shelter, supporting structures and perches for sit-and-wait predators and hence increase their predation rates. We tested the effect of habitat structure on prey mortality in aquatic invertebrates in short-term laboratory predation trials that differed in the presence or absence of artificial vegetation. The effect of habitat structure on prey mortality was context dependent as it changed with predator and prey microhabitat use. Specifically, we observed an 'antirefuge' effect of added vegetation: phytophilous predators that perched on the plants imposed higher predation pressure on planktonic prey, while mortality of benthic prey
\end{abstract}

Communicated by Joel Trexler.

Electronic supplementary material The online version of this article (doi:10.1007/s00442-014-3007-6) contains supplementary material, which is available to authorized users.

J. Klecka · D. S. Boukal

Department of Ecosystems Biology, Faculty of Science,

University of South Bohemia, Branišovská 31,

České Budějovice 37005, Czech Republic

J. Klecka · D. S. Boukal

Biology Centre of the Academy of Sciences of the Czech

Republic, v.v.i., Institute of Entomology, Branišovská 31,

České Budějovice 37005, Czech Republic

J. Klecka $(\bowtie)$

Department of Fish Ecology and Evolution, Eawag: Swiss

Federal Institute of Aquatic Science and Technology,

Seestrasse 79, 6047 Kastanienbaum, Switzerland

e-mail: jan.klecka@eawag.ch; jan.klecka@entu.cas.cz decreased. Predation by benthic and planktonic predators on either type of prey remained unaffected by the presence of vegetation. Our results show that the effects of habitat structure on predator-prey interactions are more complex than simply providing prey refuges or cover for predators. Such context-specific effects of habitat complexity may alter the coupling of different parts of the ecosystem, such as pelagic and benthic habitats, and ultimately affect food web stability through cascading effects on individual life histories and trophic link strengths.

Keywords Predation · Predator-prey interactions . Habitat complexity $\cdot$ Aquatic insects

\section{Introduction}

Habitat structure often decreases prey mortality by providing refuges for prey or by hindering the movement of predators or their ability to detect prey (e.g. Savino and Stein 1982; Dionne et al. 1990; Burks et al. 2001; Denno et al. 2005; Hauzy et al. 2010; Alexander et al. 2012). On the other hand, habitat structure can also benefit ambush predators by providing cover (e.g. Howard and Koehn 1985; Flynn and Ritz 1999; Horinouchi et al. 2009) and perching predators by improving their prey detection (e.g. Cresswell et al. 2010). In aquatic ecosystems, structured habitats may also promote facilitation between predators foraging in the open water and predators foraging in vegetation, because the prey cannot use either habitat as a refuge (Swisher et al. 1998; Eklöv and VanKooten 2001; Meerhoff et al. 2007; Grabowski et al. 2008).

Habitat structure can therefore alter the strength of predator-prey interactions in multispecies systems (Diehl 1992; Swisher et al. 1998; Carter et al. 2010) with possible 
consequences for food web stability (McCann et al. 2005). For example, habitat complexity may desynchronize unstable predator-prey dynamics over larger spatial scales and hence stabilize predator-prey dynamics (Huffaker 1958; de Roos et al. 1991). Prey refuges also weaken the effect of predators on the prey community (Crowder and Cooper 1982; Swisher et al. 1998) with positive effects on local species diversity (Diehl 1992). Understanding when habitat structure benefits prey and when it benefits predators in needed to explain the variation of community structure among different habitats and to predict the consequences of habitat alterations for individual life histories and population and community dynamics.

Predator and prey traits, particularly their microhabitat use and behaviour, may influence the effects of habitat structure on prey mortality (e.g. Burks et al. 2001). Previous studies in aquatic and terrestrial habitats showed that vegetation can serve as a refuge against different types of predators for prey living in the water column (e.g. Manatunge et al. 2000; Burks et al. 2001), on the bottom and among the vegetation (e.g. Eklöv and Diehl 1994; Denno et al. 2005). On the contrary, vegetation may elevate mortality caused by ambush predators that use it as a cover (Howard and Koehn 1985; Flynn and Ritz 1999; Horinouchi et al. 2009). Finally, some studies did not find a significant effect of vegetation on prey mortality (Lombardo 1997; Warfe and Barmuta 2004; Delclos and Rudolf 2011).

These variable effects likely reflect the role of prey and predator traits, such as body size and foraging mode that are known to affect predation (Wirtz 2012; Klecka and Boukal 2013; Klecka 2014). For example, Eklöv and Diehl (1994) found that prey refuges decrease hunting success in an ambush predator, pike (Esox lucius), much less than in the more actively hunting perch (Perca fluviatilis). Similarly, the presence of seagrass mats decreases the mortality of gobies when subjected to a chasing predator, but increases their mortality caused by an ambush predator (Horinouchi et al. 2009). The effect of habitat structure may also depend on body size of predators and prey relative to the size of spaces within the structure (e.g. size of crevices or distance between plant stems). The refuge effect is maximized when the predators cannot follow prey inside the structure (Bartholomew et al. 2000; Bartholomew 2002; Toscano and Griffen 2013).

When is habitat structure, such as submerged and emergent macrophytes in aquatic habitats, directly beneficial for predators? This can happen in at least three ways:

1. Predators may rely entirely on the presence of habitat structure to capture prey, e.g. most web-building spiders require vegetation to support their webs; some of them build webs in vegetation along river banks to catch emerging aquatic insects (e.g. Iwata 2007).
2. Habitat structure may provide cover for ambush predators that can launch surprise attacks against moving prey before they are detected. The presence of vegetation should increase prey mortality in such cases (Howard and Koehn 1985; Flynn and Ritz 1999; Horinouchi et al. 2009).

3. Habitat structure may provide perching sites and thereby improve prey detection and increase predation rates in visually hunting predators that actively pursue their prey [e.g. raptorial birds (Cresswell et al. 2010)]. In aquatic habitats, perching on submerged macrophytes is characteristic for damselfly and some dragonfly larvae that employ sit-and-wait foraging tactics; this may be an efficient way to forage on zooplankton (Convey 1988; Johnson 1991; Giacomini and De Marco 2008), which are the preferred prey of many smaller odonates (reviewed by Klecka and Boukal 2012).

Prey susceptibility to predators employing these foraging tactics is likely to depend on prey behaviour and microhabitat use (Klecka and Boukal 2012, 2013; Boukal 2014). It is likely that the predators will benefit from added structural complexity if they feed on active prey that can be intercepted or detected from shelters or perching sites. Predation rate is then a result of the benefits for predators generated by the added structure and the costs of impaired prey detection and prey hiding in refuges.

Here we focus on the third mechanism detailed above and test the hypothesis that the effect of added submerged vegetation in aquatic habitats differs among predator-prey combinations with different microhabitat use. We consider two types of prey based on their microhabitat choice: benthic (found primarily at or just above the bottom) and planktonic (or pelagic, found primarily in the water column). We distinguish three types of predators on the basis of their main foraging habitat: in addition to benthic and planktonic predators, we also include phytophilous predators that are mostly found at or among vegetation.

We use predatory aquatic insects as a highly suitable model group: they occur across many habitat types differing in complexity, which is frequently determined by the presence and amount of submerged plants (Kovalenko et al. 2012). They include all three predator types (benthic, planktonic and phytophilous), display a range of foraging behaviours and can feed on various prey that differ in habitat use and antipredator behaviour (Peckarsky 1984; Klecka and Boukal 2012, 2013). We test the impact of habitat complexity on predator-prey interactions in multiple-choice predation experiments in the presence and absence of artificial vegetation. We expect to find mostly a refuge effect of added vegetation but also that the vegetation may increase predation in phytophilous predators feeding on planktonic 
Table 1 List of species used in the spring and summer series of experiments, classified by their microhabitat use

\begin{tabular}{|c|c|c|c|c|}
\hline Series & Microhabitat use & Predator & Prey & $N_{\text {prey }}$ \\
\hline \multirow[t]{9}{*}{ Spring } & \multirow[t]{5}{*}{ Benthic } & Libellula depressa L (small, $7.9 \mathrm{~mm}$ ) & Chironomus sp. L small (6.1 mm) & 12 \\
\hline & & Libellula depressa $\mathrm{L}$ (last instar, $20.8 \mathrm{~mm}$ ) & Cloeon dipterum $\mathrm{L}(6.4 \mathrm{~mm})$ & 12 \\
\hline & & Notonecta glauca $\mathrm{L} 2(4.3 \mathrm{~mm})$ & \multirow[t]{3}{*}{ Rana sp. tadpoles (24.1 mm) } & \multirow[t]{3}{*}{6} \\
\hline & & Hydroglyphus geminus adult (2.4 mm) & & \\
\hline & & Laccophilus minutus adult (4.6 mm) & & \\
\hline & Planktonic & Chaoborus sp. L (11.1 mm) & Simocephalus vetulus adult (1.7 mm) & 30 \\
\hline & \multirow[t]{3}{*}{ Phytophilous } & Coenagrion sp. L (last instar, $13.6 \mathrm{~mm}$ ) & \multirow[t]{3}{*}{-} & \\
\hline & & Platycnemis pennipes $\mathrm{L}$ (small, $8.2 \mathrm{~mm}$ ) & & \\
\hline & & Sympetrum sanguineum L (small, $9.1 \mathrm{~mm}$ ) & & \\
\hline \multirow[t]{9}{*}{ Summer } & \multirow[t]{5}{*}{ Benthic } & Libellula depressa $\mathrm{L}$ (last instar, $23.0 \mathrm{~mm}$ ) & Chironomus sp. L (large, $8.5 \mathrm{~mm}$ ) & 10 \\
\hline & & Notonecta glauca adult (14.3 mm) & Chironomus sp. L (small, $5.4 \mathrm{~mm}$ ) & 10 \\
\hline & & Laccophilus minutus L3 (5.3 mm) & Cloeon dipterum $\mathrm{L}(3.7 \mathrm{~mm})$ & 20 \\
\hline & & Laccophilus minutus adult (4.6 mm) & \multirow[t]{2}{*}{ Sigara sp. L (2.6 mm) } & \multirow[t]{2}{*}{10} \\
\hline & & Potamonectes canaliculatus adult (5.3 mm) & & \\
\hline & Planktonic & Chaoborus sp. L (11.1 mm) & Simocephalus vetulus adult (1.7 mm) & 30 \\
\hline & \multirow[t]{3}{*}{ Phytophilous } & Coenagrion sp. L (last instar, $13.6 \mathrm{~mm}$ ) & \multirow[t]{3}{*}{-} & \\
\hline & & Platycnemis pennipes $\mathrm{L}$ (small, $8.2 \mathrm{~mm}$ ) & & \\
\hline & & Sympetrum sanguineum $\mathrm{L}$ (last instar, $16.2 \mathrm{~mm}$ ) & & \\
\hline
\end{tabular}

Mean body length is given in parentheses

$N_{\text {prey }}$ Number of prey individuals used in each experiment, $L$ larva, $L 2$ second-instar larva, $L 3$ third-instar larva

prey by providing perching sites to the predators (the third mechanism detailed above). We term this phenomenon the 'anti-refuge' effect of aquatic vegetation.

\section{Materials and methods}

Experiments were run in transparent plastic boxes filled with 41 of tap water aged for 1 day (bottom surface $26 \times 14 \mathrm{~cm}$, depth ca. $11 \mathrm{~cm}$ ) and a 5-mm-thick layer of sand and fine gravel (grain size $<3 \mathrm{~mm}$ ) at the bottom. The vegetation was made of ten 'leaves' (strips of green plastic mesh, $20 \mathrm{~cm}$ long, $5 \mathrm{~cm}$ wide, mesh size ca. $5 \times 2 \mathrm{~mm}$ when stretched and considerably smaller under experimental conditions) joined into a tuft and placed in the middle of the box. The leaves intersected the whole water column and reached all sides of the box. The experimental conditions corresponded to moderately vegetated pools and littoral zones of ponds in the study area where we collected the prey and predators for the experiment. We used artificial vegetation to isolate the effect of habitat structure from potential effects of foraging behaviour at lower trophic levels: live plants could have been perceived as food patches by some of the prey used in the experiment and could have altered its behaviour. The sides of the experimental boxes were shielded by sheets of brown paper to prevent disturbance of the experiments by observer movement and visual interference of the predators.
Laboratory experiments were run in May 2010 (hereafter referred to as the 'spring series') and in June-July 2010 (referred to as the 'summer series') to cover seasonal turnover of the most common predators and their prey in the field. Predators and prey were collected in small pools in a reclaimed sandpit area near Suchdol nad Lužnicí (Czech Republic; $48^{\circ} 55^{\prime} 04^{\prime \prime} \mathrm{N}, 14^{\circ} 52^{\prime} 55^{\prime \prime} \mathrm{E}$ ). We used nine types of locally common predatory aquatic insects in each series of experiments (Table 1), including larvae of damselflies and dragonflies, larvae and adults of a backswimmer, adults and larvae of diving beetles and Chaoborus midge larvae. Zooplankton in the pools were dominated by the cladoceran Simocephalus vetulus, and we used it each time together with three or four of the other commonest prey species that are typically benthic (Table 1 ).

Experiments were performed in a climate room with a regular temperature cycle (day, maximum $22{ }^{\circ} \mathrm{C}$; night, minimum $18{ }^{\circ} \mathrm{C}$; average $20{ }^{\circ} \mathrm{C}$ ) and photoperiod (day, $18 \mathrm{~h}$; night, $6 \mathrm{~h}$ ). Animals collected in the field were acclimated in the room for 2-3 days prior to experiments. Predators were kept individually in small containers with $0.25-0.71$ of water and fed daily ad libitum with a mixture of natural prey collected at the study site (the same set of prey species as used in the experiment). They were starved for $24 \mathrm{~h}$ prior to the experiment to standardize their hunger level. At the start of each experiment, all prey were released in the vessel and allowed to settle for ca. 5 min before one predator individual was introduced. Prey density was 
chosen to approximate natural densities at the study site (J. Klecka and D. S. Boukal, unpublished data). Surviving prey were counted after $24 \mathrm{~h}$. Six replicates with vegetation and six without vegetation were conducted with each predator species (seven with Sympetrum without vegetation in the spring series); i.e. a total of 109 experiments were carried out in the spring and 108 in the summer series. Each individual predator was used only once. Natural mortality of most prey, evaluated in eight controls (four with and four without vegetation; Table S1), was negligible $(<3 \%)$ and thus had no effect on the results. Only Simocephalus had higher mortality in the summer experiments $(4.6 \%)$, which corresponded to one individual per replicate dying from causes other than predation.

Microhabitat use of predators and prey was classified based on observed behaviour at the start of the experiment, occasional observations during the experiment and the prevailing positions of the individuals at the end of the experiment. All species could be easily classified to one of the three categories (benthic, planktonic and phytophilous) because they displayed clear microhabitat selectivity. Prey always resided in their preferred microhabitat and predators were only rarely observed outside their preferred microhabitat $(0-30 \%$ of observations in individual species).

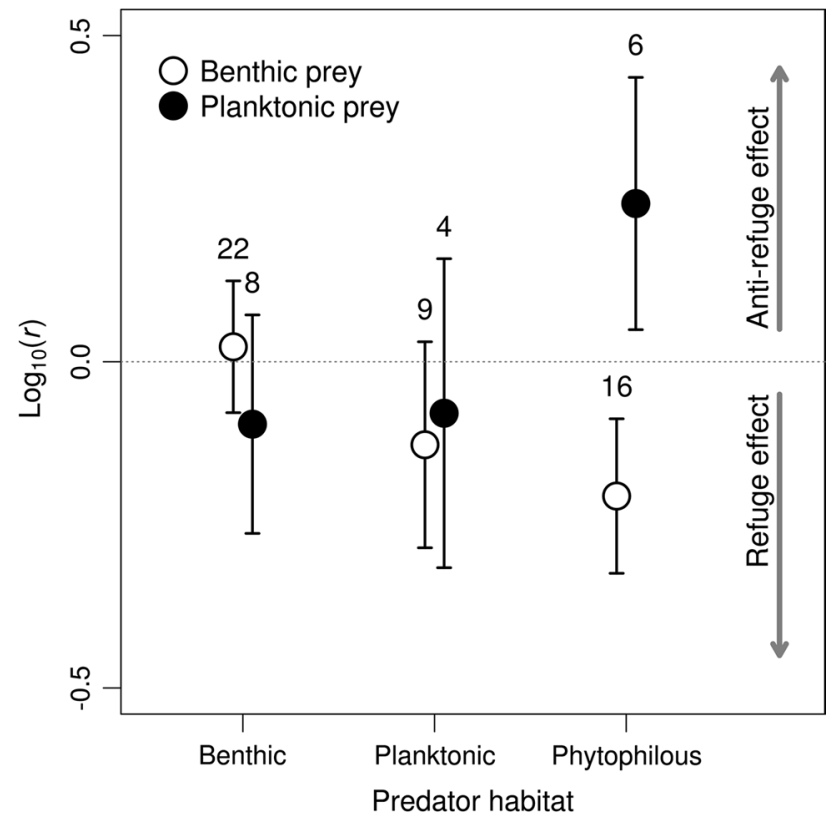

Fig. 1 Mortality ratio $\log _{10}(r)$ of the number of prey consumed in the presence of artificial vegetation compared to that in the absence of vegetation (mean and $\pm 95 \%$ confidence interval). Predators and prey are grouped by their microhabitat use; the number of observations for individual combinations is shown above the error bars (total $n=65$ ). Negative values indicate that prey suffered lower mortality in the presence of vegetation (refuge effect). Positive values indicate that vegetation enhanced prey consumption (anti-refuge effect)
Fig. 2 Mortality of individual prey species caused by predation by different species of predators in the spring and summer series of experiments. Mortality was measured as the proportion of prey individuals consumed during an experiment. Filled circles show mortality in the presence of vegetation, while empty circles show mortality in the absence of vegetation. Vertical bars denote \pm 1 SE. The number of observations for each predator was six with vegetation and six without vegetation in the spring as well as in the summer (seven in Sympetrum without vegetation in the spring series). Details on the species used are provided in Table 1

For each predator-prey combination, we calculated prey mortality in individual experiments as the proportion of prey individuals consumed by the predator. We then calculated the ratio $r$ of mortality caused by the predator in the presence of vegetation over that in the absence of vegetation, $r=N_{1} / N_{2}$, where $N_{1}$ and $N_{2}$ are respectively the numbers of prey individuals eaten by the predator in the presence and absence of vegetation. This formulation corresponds to a response ratio used frequently in meta-analyses (Osenberg et al. 1997, 1999; Hedges et al. 1999). We tested how the $\log _{10}$-transformed mortality ratio $r$ depends on predator and prey microhabitat association, classified as in Table 1 using a generalised linear model (GLM; normal distribution) in R 2.15.1 (R Core Team 2012).

\section{Results}

Mortality of individual prey species exposed to different predators varied from 0 to $100 \%$ in individual replicates (Table S1). Each predator except the smallest one, the diving beetle Hydroglyphus, caused substantial mortality (>30\%) to at least one prey when averaged across replicates (Table S2). Microhabitat association of predators and prey modified the effect of vegetation on prey mortality (Fig. 1): the ratio of the number of prey consumed in the presence of artificial vegetation compared to that in the absence of vegetation measured as $\log _{10}(r)$ was significantly affected by the interaction of the predator and prey microhabitat use (GLM, $F_{2,59}=6.99, P=0.002$; Fig. 1). Mortality of planktonic prey (Simocephalus) caused by phytophilous predators (three odonate species) increased on average 1.7 times with added vegetation. This contrasted with decreased mortality of benthic prey such as Chironomus larvae (Fig. 1; Table S2). Mortality caused by benthic and planktonic predators did not differ significantly in either type of prey in the presence and absence of vegetation (Fig. 1), contrary to the general expectation of vegetation acting as a refuge. These patterns were consistent in time as there was no significant effect of time period on the result (GLM, test of a three-way interaction of prey habitat $\times$ predator habitat $\times$ time period, $F_{2,53}=1.21, P=0.31$ ).

More detailed analysis of prey mortality in individual predator-prey combinations supports the results based 
Spring
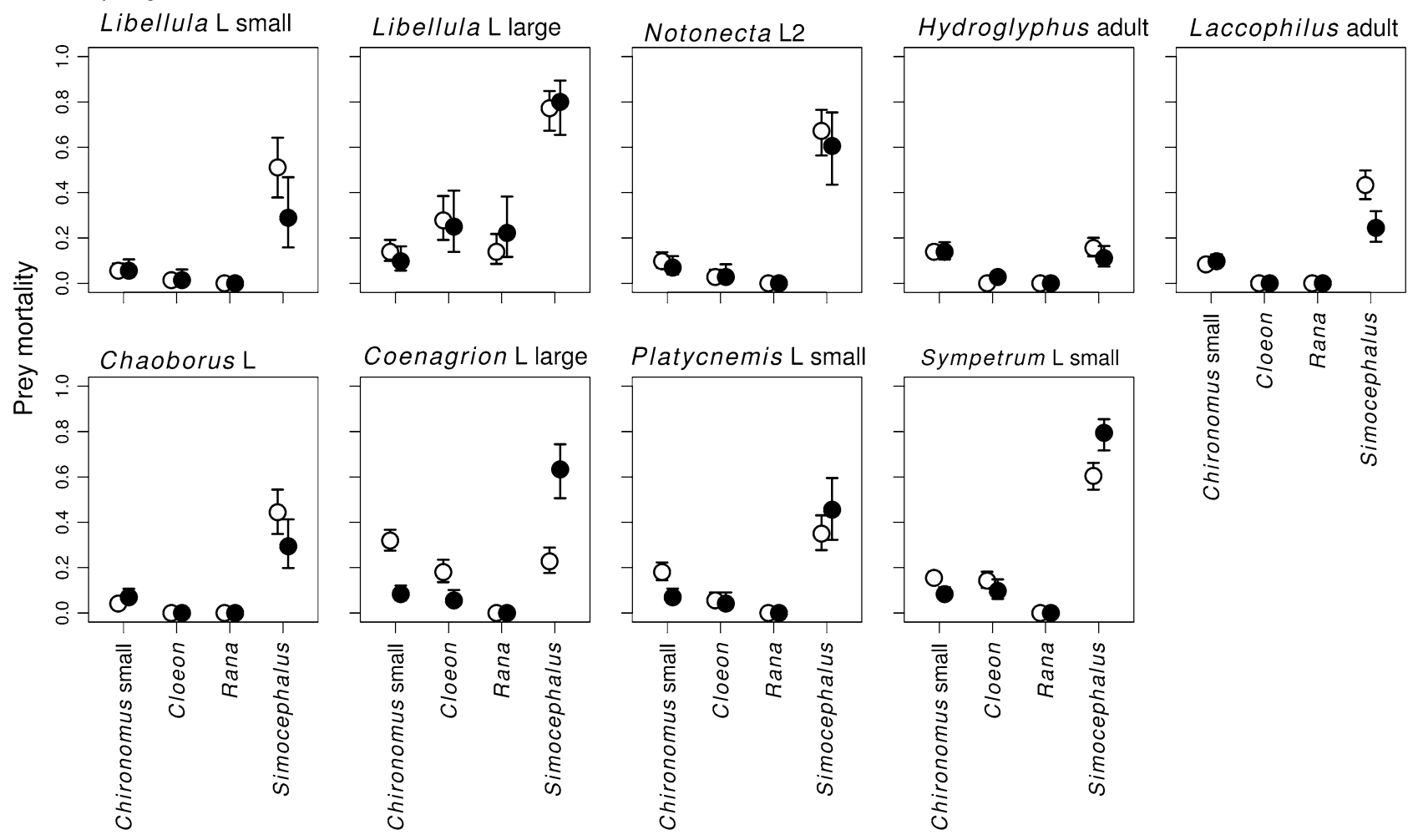

\section{Summer}
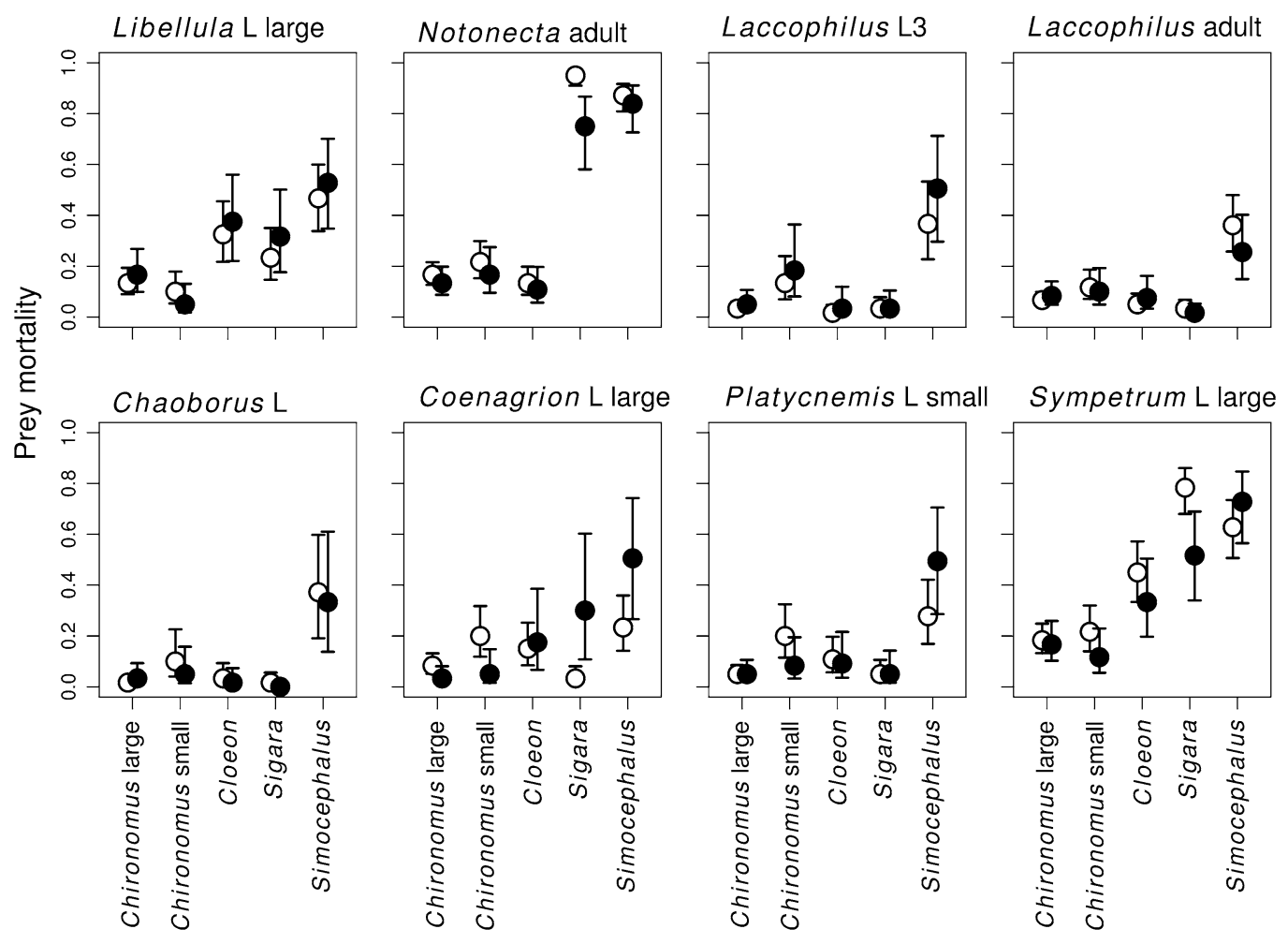

Potamonectes adult
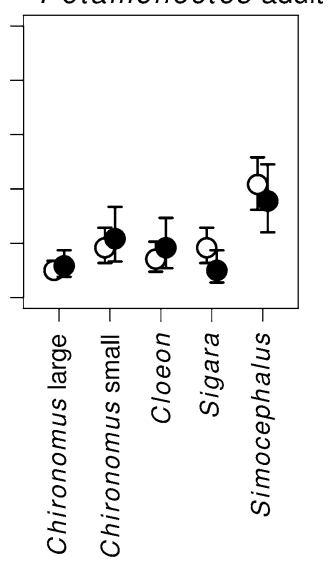

Prey species 
on species classification according to microhabitat choice (Fig. 2). In most cases, the vegetation had little effect on prey mortality. Some combinations were suggestive of the refuge effect, e.g. the mortality of small Chironomus larvae caused by Coenagrion, Platycnemis and Sympetrum was slightly lower in the presence of the vegetation in both the spring and summer series of experiments (Fig. 2). Adult Laccophilus also caused lower mortality of Simocephalus in the spring series, but this effect was much weaker in the summer experiments. On the other hand, mortality of Simocephalus caused by Coenagrion, Platycnemis and Sympetrum was consistently higher in the presence of vegetation (Fig. 2). Some results are not attributable solely to the predator and prey microhabitat use. Most notably, mortality of the benthic prey Sigara caused by adult Notonecta and large Sympetrum was lower in the presence of the vegetation and hence suggestive of a refuge effect, but its mortality caused by large Coenagrion increased when the vegetation was present. However, the majority of interspecific differences are consistent with predator and prey microhabitat use as shown in Fig. 1.

\section{Discussion}

The impact of artificial vegetation on prey mortality in our experiment was context specific and depended on the microhabitat use of predators and prey. Prey mortality did not change significantly for many predator-prey pairs but we observed an anti-refuge effect in planktonic prey (Simocephalus) and phytophilous predators (damselflies Coenagrion and Platycnemis and one species of dragonfly, Sympetrum). The vegetation provided perching sites for these predators, which gained access to and increased their predation pressure on Simocephalus. These odonate larvae are largely sit-and-wait predators (Peckarsky 1984) and zooplankton are among their preferred prey (Klecka and Boukal 2012). Their ability to forage on the zooplankton in the water column depended strongly on the availability of perching sites, and larvae that used perching sites also consumed fewer benthic prey (Figs. 1,2). This indicates that vegetation may increase predation on zooplankton and at the same time release benthic prey from predation in habitats dominated by phytophilous odonates, such as in ponds and shallow lakes with dense submerged or emerged vegetation.

In an earlier similar experiment, Convey (1988) observed predation by Coenagrion puella and Ischnura elegans on zooplankton (Daphnia sp.) in the presence and absence of perches. He reported higher capture success rate in perching individuals, but lower frequency of attacks as well as kills per unit time compared to individuals sitting on the bottom, which disagrees with our results. This can be explained by the observation that Daphnia tended to stay close to the bottom after they were released into the experimental arena, so that bottom-dwelling predators had higher encounter rates with prey than perching predators (Convey 1988). In our case, Simocephalus were distributed in the entire water column and their encounter rates with phytophilous predators were at least as high or higher in the presence of vegetation.

Positive effect of perching sites may be more widespread and extend beyond aquatic habitats. Web-building spiders (Iwata 2007) and raptorial birds (Cresswell et al. 2010) also benefit from the presence of trees and other elevated structures, even if the mechanisms through which perching sites increase foraging success in these predator groups are different. Web-building spiders require vegetation or rocks to anchor their webs and the birds employ a sit-andpursue foraging tactic and use perches only to improve their chance to visually detect prey (Cresswell et al. 2010), while the phytophilous odonate larvae used in our experiments were able to capture planktonic prey passing by their perches. It is likely that these mechanisms benefit predators mainly at low to intermediate levels of habitat complexity (Flynn and Ritz 1999). In a habitat with dense vegetation, the benefits of the structure for predators may be outweighed by the costs of impaired prey detection, numerous prey refuges and diminished prey capture success (Gotceitas and Colgan 1989; Flynn and Ritz 1999).

Numerous studies have tested how prey mortality changes along a gradient of habitat complexity and different functional relationships have been found. For example, Nelson and Bonsdorff (1990) found that the predation rate of perch (Perca fluviatilis) feeding on sticklebacks decreased linearly with increasing vegetation density, while other studies found nonlinear relationships between vegetation density and predation rate (Savino and Stein 1982; Gotceitas and Colgan 1989; Flynn and Ritz 1999; Canion and Heck 2009). This variation may reflect the details of predator and prey behaviour in differently structured environments, such as switching between searching and ambush foraging modes (Savino and Stein 1982; Michel and Adams 2009), prey choice of refuge habitat (Gotceitas and Colgan 1989) or the differential abilities of predators to forage in the refuge (Burks et al. 2001).

Despite the prevailing view that habitat structure provides refuges to prey, a number of experimental studies found no refuge effect. For example, two experiments with damselfly larvae reported no effect of varying habitat complexity on their predation rates (Lombardo 1997; Delclos and Rudolf 2011) and James and Heck (1994) found only a limited effect of vegetation complexity on predation pressure of fish on invertebrates. Our experiments corroborate these earlier studies: predation pressure by benthic and planktonic predators on both benthic and planktonic prey 
was virtually unaffected by the presence of vegetation. These conclusions contrast with numerous other experiments illustrating the role of vegetation as a source of refuges for prey in grassland habitats (Langellotto and Denno 2004; Denno et al. 2005; Sanders et al. 2008) and in freshwater (Gotceitas and Colgan 1989; Nelson and Bonsdorff 1990; Eklöv and Diehl 1994; Manatunge et al. 2000; Warfe and Barmuta 2006) and marine systems (James and Heck 1994; Almany 2004; Alexander et al. 2012).

Finally, there is mounting evidence that habitat structure can benefit predators by providing cover for them when they attack prey from ambush (Howard and Koehn 1985; Flynn and Ritz 1999; Horinouchi et al. 2009) and by improving prey detection in perching predators (Cresswell et al. 2010). The importance of foraging behaviour for determining the role of vegetation for prey mortality has been demonstrated, for example, by Horinouchi et al. (2009), who found that submerged vegetation increased foraging efficiency of an ambush marine predator and led to the opposite effect in a searching predator. Some spiders also forage more efficiently in more complex environments (Denno et al. 2002). In addition, habitat structure can alter prey mortality rates in multi-predator environments, e.g. when predators foraging in open water facilitate predators in the vegetation (Swisher et al. 1998; Eklöv and VanKooten 2001; Grabowski et al. 2008). Together, these and our own results clearly show that the refuge effect of habitat structure is not universal and that several mechanisms can lead to higher predation rates in structurally more complex environments.

Our experiment, as well as most previously published studies, used constant predator and prey densities while varying the presence or density of vegetation or other types of habitat structure. Several recent papers argued that a more realistic experimental set up would be to vary densities of predators and prey together with vegetation because population densities are often higher in vegetated habitats (Mattila et al. 2008; Canion and Heck 2009; Scheinin et al. 2012). These studies found a refuge effect when comparing the presence and absence of vegetation, but little or no effect of vegetation density on prey mortality. This result could be ascribed to the balancing effects of increased predator-prey encounter rates due to increased predator and/or prey densities and decreased encounter rates due to increasing vegetation density (Mattila et al. 2008; Canion and Heck 2009; Scheinin et al. 2012). However, a proportional increase of prey and predator density with vegetation density is not a general phenomenon; i.e. preference for vegetated or open habitats is taxon specific (de Szalay and Resh 2000; Tolonen et al. 2003). Population densities may increase with vegetation density for many reasons (availability of food, refuge, structure for laying eggs, etc.).
Testing the role of habitat complexity with constant predator and prey abundances may help to explain why some species are more abundant in dense vegetation. Experimental approaches with constant as well as variable prey densities thus have their merits and provide complementary information.

In conclusion, we showed that the same structure may simultaneously serve as prey refuge, increase predation pressure or have no effect for certain predator and prey trait combinations. In general, predation mortality depends on multiple traits including body mass, foraging behaviour of predators and escape behaviour of prey (Klecka and Boukal 2013; Klecka 2014). These direct effects of body mass, foraging behaviour and microhabitat use can combine with indirect behavioural effects (Swisher et al. 1998; Schmitz et al. 2004) and determine how changes in habitat structure modify individual life histories and population and food web dynamics. Phytophilous predators may benefit from the presence of structure and achieve higher individual and population growth rates. Moreover, most predators feed on at least several prey species and the presence and density of vegetation often alter their prey selectivity and lead to changes in prey community composition (Diehl 1992; Carter et al. 2010). In turn, most prey species are subject to predation by multiple predators and the presence or density of habitat structure may alter the risk of predation by different predators and either increase or decrease the combined predator effect on prey survival by altering the level of interference or intraguild predation between predator species (Swisher et al. 1998; Eklöv and VanKooten 2001; Grabowski et al. 2008). For example, zooplankton that migrate toward vegetated littoral habitats to avoid planktivorous fish in the open water can fall prey to littoral macroinvertebrates (Meerhoff et al. 2007).

Changes in habitat complexity can thereby affect the structure and stability of entire food webs by altering the pattern of interaction strengths through a combination of direct effects of habitat structure on consumption rates and indirect effects mediated by behavioural changes and phenotypic plasticity of individual species. Apart from changing the strength of predator-prey interactions at the habitat and microhabitat scale, such varied consequences of habitat complexity may alter the importance of alternative pathways of energy transfer and the coupling of different parts of the entire ecosystem, such as pelagic and benthic habitats in lakes (e.g. Dolson et al. 2009).

Acknowledgments We thank A. P. Beckerman, L. Berec, D. J. Mikolajewski and anonymous reviewers for comments that helped us improve the manuscript at various stages of preparation. The study was supported by the Grant Agency of the University of South Bohemia (GAJU 145/2010/P), the EU Marie Curie European Reintegration Grant AquaMod to D. S. B. (PERG04-GA-2008-239543) and 
the Grant Agency of the Czech Republic (grant no. P505/10/0096). The use of tadpoles in the experiment was permitted by the regional authority (permit no. KUJCK 12524/2010 OZZL/2/Do) and the Ministry of Education of the Czech Republic (permit no. 7947/2010 30).

\section{References}

Alexander ME, Dick JTA, O'Connor NE, Haddaway NR, Farnsworth KD (2012) Functional responses of the intertidal amphipod Echinogammarus marinus: effects of prey supply, model selection and habitat complexity. Mar Ecol Progr Ser 468:191-202. doi: $10.3354 /$ meps09978

Almany GR (2004) Differential effects of habitat complexity, predators and competitors on abundance of juvenile and adult coral reef fishes. Oecologia 141:105-113. doi:10.1007/s00442-004-1617-0

Bartholomew A (2002) Total cover and cover quality: predicted and actual effects on a predator's foraging success. Mar Ecol Prog Ser 227:1-9. doi:10.3354/meps 227001

Bartholomew A, Diaz RJ, Cicchetti G (2000) New dimensionless indices of structural habitat complexity: predicted and actual effects on a predator's foraging success. Mar Ecol Prog Ser 206:45-58. doi:10.3354/meps206045

Boukal DS (2014) Trait- and size-based descriptions of trophic links in freshwater food webs: current status and perspectives. J Limnol 73:171-185. doi:10.4081/jlimnol.2014.826

Burks RL, Jeppesen E, Lodge DM (2001) Littoral zone structures as Daphnia refugia against fish predators. Limnol Oceanogr 46:230-237. doi:10.4319/1o.2001.46.2.0230

Canion CR, Heck KL Jr (2009) Effect of habitat complexity on predation success: re-evaluating the current paradigm in seagrass beds. Mar Ecol Prog Ser 393:37-46. doi:10.3354/meps08272

Carter MW, Shoup DE, Dettmers JM, Wahl DH (2010) Effects of turbidity and cover on prey selectivity of adult smallmouth bass. Trans Am Fish Soc 139:353-361. doi:10.1577/T08-159.1

Convey P (1988) Competition for perches between larval damselflies: the influence of perch use on feeding efficiency, growth rate and predator avoidance. Freshwater Biol 19:15-28. doi:10.1111/j.1365-2427.1988.tb00323.x

Cresswell W, Lind J, Quinn JL (2010) Predator-hunting success and prey vulnerability: quantifying the spatial scale over which lethal and non-lethal effects of predation occur. J Anim Ecol 79:556562. doi:10.1111/j.1365-2656.2010.01671.x

Crowder LB, Cooper WE (1982) Habitat structural complexity and the interaction between bluegills and their prey. Ecology 63:1802-1813. doi:10.2307/1940122

de Roos AM, McCauley E, Wilson WG (1991) Mobility versus density-limited predator-prey dynamics on different spatial scales. Proc R Soc B 246:117-122. doi:10.1098/rspb.1991.0132

de Szalay F, Resh VH (2000) Factors influencing macroinvertebrate colonization of seasonal wetlands: responses to emergent plant cover. Freshwater Biol 45:295-308. doi:10.1111/j.1365-2427.2000.00623.x

Delclos P, Rudolf VHW (2011) Effects of size structure and habitat complexity on predator-prey interactions. Ecol Entomol 36:744750. doi:10.1111/j.1365-2311.2011.01324.x

Denno RF, Gratton C, Peterson MA, Langellotto GA, Finke DL, Huberty AF (2002) Bottom-up forces mediate natural-enemy impact in a phytophagous insect community. Ecology 83:14431458. doi: $10.2307 / 3071956$

Denno RF, Finke DL, Langellotto GA (2005) Direct and indirect effects of vegetation structure and habitat complexity on predator-prey and predator-predator interactions. In: Barbosa P, Castellanos I (eds) Ecology of predator-prey interactions. Oxford University Press, Oxford, UK, pp 211-239
Diehl S (1992) Fish predation and benthic community structure: the role of omnivory and habitat complexity. Ecology 73:1646-1661. doi: $10.2307 / 1940017$

Dionne M, Butler M, Folt C (1990) Plant-specific expression of antipredator behaviour by larval damselflies. Oecologia 83:371-377. doi:10.1007/BF00317562

Dolson R, McCann K, Rooney N, Ridgway M (2009) Lake morphometry predicts the degree of habitat coupling by a mobile predator. Oikos 118:1230-1238. doi:10.1111/j.1600-0706.2009.17351.x

Eklöv P, Diehl S (1994) Piscivore efficiency and refuging prey: the importance of predator search mode. Oecologia 98:344-353. doi: 10.1007/BF00324223

Eklöv P, VanKooten T (2001) Facilitation among piscivorous predators: effects of prey habitat use. Ecology 82:2486-2494. doi:10.1890/0012-9658(2001)082[2486:FAPPEO]2.0.CO;2

Flynn AJ, Ritz (1999) Effect of habitat complexity and predatory style on the capture success of fish feeding on aggregated prey. J Mar Biol Assoc UK 79:487-494

Giacomini HC, De Marco P (2008) Larval ecomorphology of 13 Libellulidae (Anisoptera, Odonata) of the Middle Rio Doce Valley, Minas Gerais, Brazil. Braz J Biol 68:211-219. doi:10.1590/ S1519-69842008000100031

Gotceitas V, Colgan P (1989) Predator foraging success and habitat complexity: quantitative test of the threshold hypothesis. Oecologia 80:158-166

Grabowski JH, Hughes AR, Kimbro DL (2008) Habitat complexity influences cascading effects of multiple predators. Ecology 89:3413-3422. doi:10.1890/07-1057.1

Hauzy C, Tully T, Spataro T, Paul G, Arditi R (2010) Spatial heterogeneity and functional response: an experiment in microcosms with varying obstacle densities. Oecologia 163:625-636. doi:10.1007/ s00442-010-1585-5

Hedges LV, Gurevitch J, Curtis PS (1999) The meta-analysis of response ratios in experimental ecology. Ecology 80:1150-1156. doi:10.1890/0012-9658(1999)080[1150:TMAORR]2.0.CO;2

Horinouchi M, Mizuno N, Jo Y, Fujita M, Sano M, Suzuki Y (2009) Seagrass habitat complexity does not always decrease foraging efficiencies of piscivorous fishes. Mar Ecol Prog Ser 377:43-49. doi: 10.3354/meps07869

Howard RK, Koehn JD (1985) Population dynamics and feeding ecology of pipefish (Syngnathidae) associated with Eelgrass beds of Western Port, Victoria. Aust J Mar Freshwater Res 36:361-370

Huffaker CB (1958) Experimental studies on predation: dispersion factors and predator-prey oscillations. Hilgardia 27:795-835

Iwata T (2007) Linking stream habitats and spider distribution: spatial variations in trophic transfer across a forest-stream boundary. Ecol Res 22:619-628. doi:10.1007/s11284-006-0060-6

James PL, Heck KJ (1994) The effects of habitat complexity and light intensity on ambush predation within a simulated seagrass habitat. J Exp Mar Biol Ecol 176:187-200. doi:10.1016/0022-0981(94)90184-8

Johnson DM (1991) Behavioral ecology of larval dragonflies and damselflies. Trends Ecol Evol 6:8-13. doi:10.1016/0169-5347(91)90140-S

Klecka J (2014) The role of a water bug, Sigara striata, in freshwater food webs. PeerJ 2:e389. doi:10.7717/peerj.389

Klecka J, Boukal DS (2012) Who eats whom in a pool? A comparative study of prey selectivity by predatory aquatic insects. PLoS ONE 7:e37741. doi:10.1371/journal.pone.0037741

Klecka J, Boukal DS (2013) Foraging and vulnerability traits modify predator-prey body mass allometry: freshwater macroinvertebrates as a case study. J Anim Ecol 82:1031-1041. doi:10.1111/1365-2656.12078

Kovalenko KE, Thomaz SM, Warfe DM (2012) Habitat complexity: approaches and future directions. Hydrobiologia 685:1-17. doi:10.1007/s10750-011-0974-z 
Langellotto GA, Denno RF (2004) Responses of invertebrate natural enemies to complex-structured habitats: a meta-analytical synthesis. Oecologia 139:1-10. doi:10.1007/s00442-004-1497-3

Lombardo P (1997) Predation by Enallagma nymphs (Odonata, Zygoptera) under different conditions of spatial heterogeneity. Hydrobiologia 356:1-9. doi:10.1023/A:1003038717605

Manatunge J, Asaeda T, Priyadarshana T (2000) The influence of structural complexity on fish-zooplankton interactions: a study using artificial submerged macrophytes. Environ Biol Fishes 58:425-438. doi:10.1023/A:1007691425268

Mattila J, Heck KL Jr, Millstein E, Miller E, Gustafsson C, Williams S, Byron D (2008) Increased habitat structure does not always provide increased refuge from predation. Mar Ecol Prog Ser 361:15-20. doi:10.3354/meps07392

McCann KS, Rasmussen JB, Umbanhowar J (2005) The dynamics of spatially coupled food webs. Ecol Lett 8:513-523. doi:10.1111/j.1461-0248.2005.00742.x

Meerhoff M, Iglesias C, De Mello FT, Clemente JM, Jensen E, Lauridsen TL, Jeppesen E (2007) Effects of habitat complexity on community structure and predator avoidance behaviour of littoral zooplankton in temperate versus subtropical shallow lakes. Freshwater Biol 52:1009-1021. doi:10.1111/j.1365-2427.2007.01748.x

Michel MJ, Adams MM (2009) Differential effects of structural complexity on predator foraging behaviour. Behav Ecol 20:313-317. doi:10.1093/beheco/arp005

Nelson WG, Bonsdorff E (1990) Fish predation and habitat complexity: are complexity thresholds real? J Exp Mar Biol Ecol 141:183-194. doi:10.1016/0022-0981(90)90223-Y

Osenberg CW, Sarnelle O, Cooper SD (1997) Effect size in ecological experiments: the application of biological models in meta-analysis. Am Nat 150:798-812. doi:10.1086/286095

Osenberg CW, Sarnelle O, Cooper SD, Holt RD (1999) Resolving ecological questions through meta-analysis: goals, metrics, and models. Ecology 80:1105-1117. doi:10.2307/177058

Peckarsky BL (1984) Predator-prey interactions among aquatic insects. In: Resh VH, Rosenberg DM (eds) Ecology of aquatic insects. Praeger, New York, pp 196-254
R Core Team (2012) R: A language and environment for statistical computing. R Foundation for Statistical Computing, Vienna. http://www.R-project.org

Sanders D, Nickel H, Grützner T, Platner C (2008) Habitat structure mediates top-down effects of spiders and ants on herbivores. Basic Appl Ecol 9:152-160. doi:10.1016/j.baae.2007.01.003

Savino JF, Stein RA (1982) Predator-prey interactions between largemouth bass and bluegills as influenced by simulated vegetation. Trans Am Fish Soc 111:255-266. doi:10.1577/1548-8659(1982)111<255:PIBLBA>2.0.CO;2

Scheinin M, Scyphers SB, Kauppi L, Heck KL Jr, Mattila J (2012) The relationship between vegetation density and its protective value depends on the densities and traits of prey and predators. Oikos 121:1093-1102. doi:10.1111/j.1600-0706.2011.19941.x

Schmitz OJ, Krrivan V, Ovadia O (2004) Trophic cascades: the primacy of trait-mediated indirect interactions. Ecol Lett 7:153-163. doi:10.1111/j.1461-0248.2003.00560.x

Swisher BJ, Soluk DA, Wahl DH (1998) Non-additive predation in littoral habitats: influences of habitat complexity. Oikos 81:30 37. doi:10.2307/3546464

Tolonen KT, Hämäläinen H, Holopainen IJ, Mikkonen K, Karjalainen $\mathrm{J}$ (2003) Body size and substrate association of littoral insects in relation to vegetation structure. Hydrobiologia 499:179-190. doi: 10.1023/A: 1026325432000

Toscano BJ, Griffen BD (2013) Predator size interacts with habitat structure to determine the allometric scaling of the functional response. Oikos 122:454-462. doi:10.1111/j.1600-0706.2012.20690.x

Warfe DM, Barmuta LA (2004) Habitat structural complexity mediates the foraging success of multiple predator species. Oecologia 141:171-178. doi:10.1007/s00442-004-1644-x

Warfe DM, Barmuta LA (2006) Habitat structural complexity mediates food web dynamics in a freshwater macrophyte community. Oecologia 150:141-154. doi:10.1007/s00442-006-0505-1

Wirtz K (2012) Who is eating whom? Morphology and feeding type determine the size relation between planktonic predators and their ideal prey. Mar Ecol Prog Ser 445:1-12. doi:10.3354/meps09502 